\title{
Pretreatment for Tunnel Karst Cave during Excavation: A Case Study of Guangxi, China
}

\author{
Junjie Li, ${ }^{1}$ Qiunan Chen, ${ }^{2}$ Xiaocheng Huang $\mathbb{D}^{3},{ }^{3}$ Gen Zou, ${ }^{2}$ and Jiazheng Deng ${ }^{2}$ \\ ${ }^{1}$ Hunan Provincial Key Laboratory of Geotechnical Engineering for Stability Control and Health Monitoring, \\ Hunan University of Science and Technology, Hunan, Xiangtan 411201, China \\ ${ }^{2}$ School of Civil Engineering, Hunan University of Science and Technology, Hunan, Xiangtan 411201, China \\ ${ }^{3}$ National Engineering Laboratory of Highway Maintenance Technology, Changsha University of Science \& Technology, \\ Changsha 410114, Hunan, China
}

Correspondence should be addressed to Xiaocheng Huang; hxc@hnust.edu.cn

Received 2 June 2021; Accepted 9 August 2021; Published 15 September 2021

Academic Editor: Jie Liu

Copyright ( $(2021$ Junjie Li et al. This is an open access article distributed under the Creative Commons Attribution License, which permits unrestricted use, distribution, and reproduction in any medium, provided the original work is properly cited.

Karst landscape is a general term for earth surfaces and underground patterns that have been formed by the dissolution of soluble rock. Karst landscapes are widely distributed throughout China-particularly in the Guangxi and Guangdong provinces. The main features of karst landscapes are typically reflected in karst caverns, sinkholes, and other geographical phenomena. During tunnel construction in karst areas, various forms of karst caverns may appear on the construction route, and they can cause hazards-such as water inrush and collapse-during tunnel construction. These hazards affect the tunnel construction process. As such, it is necessary to propose a treatment for karst caverns. In this work, a case study of the tunnels on the Hechi-Baise expressway is presented. A comprehensive pretreatment method suitable for this tunnel is proposed. On the premise of prioritizing the safety and timeline of construction, an optimized treatment scheme for the karst caverns of Hebai tunnel is followed. The optimized treatment scheme primarily includes calculation of safe thickness of tunnel face, strengthening the initial support and increasing the thickness of the second lining, increasing the reserved deformation, and grouting. The proposed scheme achieved favorable results in the treatment of a karst cavern in the Hebai tunnels.

\section{Introduction}

Karst landscapes are formed as a result of the dissolution of soluble rock-particularly limestone. They have a significant degree of unpredictability and heterogeneity, by which various hazards may be caused [1-6]. It is understood that karst caverns are mainly filled with groundwater and filler [7]. During tunnel construction, water inrush, mud inrush, and collapse may occur due to karst caverns [8-13]. Hence, it is important to prepare worksites with inhomogeneous karst cavern treatment prior to tunnel construction. By this, safety and mitigation of hazards will be guaranteed during construction. Therefore, it is essential to study karst geology and take effective countermeasures to mitigate geohazards during deep excavations in karst regions with caverns [14-16].
Karst is widely distributed throughout southern China [14]. With the rapid development of infrastructure engineering in China-particularly in the tunnel and metro systems [17-19] - it is ineluctable that karst caverns will be encountered during construction in karst regions. Karst caverns can be discriminated into two types, according to the internal filler content (with or without water), or three types, according to the cavern position (at the tunnel vault, arch waist, or bottom). Besides these characteristics, high permeability, variable shapes, and collapse are features of tunnel caverns in Guangxi Province.

China's tunnel engineering is in a period of rapid development. Not only has tunnel construction technology seen many innovative developments, but also numerous construction project problems and natural obstacles have been effectively dealt with in karst areas. The impact of karst 
caverns on tunnels is immediate. For example, in the Yanglin Tunnel in Jiangsu Province, excessive water and mud inrush occurred during construction and caused large settlement [20]. More than 505 karst caverns were predicted in a case of karst regions in Guangdong Province. Finding a way to address these caverns became the most important consideration during construction. Today, the most widely used methods include the clearance-filling and beam-bridge methods, dynamic compaction, jet grouting, and sleevevalve-pipe grouting $[3,4,21]$. However, these methods have defects in construction and cannot be universally applied to tunnel caverns [14]. As such, specific treatment methods for specific karst caves are needed.

In this study, a karst tunnel was investigated and reinforced by grouting. It was known that the tunnel construction route encountered caverns and hazard mitigation needed to be performed quickly. The objectives of this paper are as follows: (i) to describe the general situation of the tunnels on the Hechi-Baise (Hebai) Expressway in Guangxi Province, as shown in Figure 1, (ii) to discuss potential geohazards and pretreatment techniques for karst caverns during tunnel construction in karst regions, and (iii) to introduce a karst cavern treatment technique for the specific position of the tunnel. This study provides feasible suggestions and concrete construction methods for similar projects and karst cave treatments in the future.

\section{Construction Site Description}

There are 4 middle and 3 short tunnels on the Hebai Expressway that are run through karst regions of China's Guangxi Province. There are small clear distance and separated left and right lanes of tunnels. Full-line tunnels use composite lining structures as flexible support system$s$-including reinforcing steel mesh, shotcrete, and I-shaped or grille steel frames-as initial supports, which allow full play to the bearing capacity of the surrounding rock. A secondary lining is made from molded concrete (or molded reinforced concrete), and a Chemical Bonding and Physical Crosslinking Synergism (CPS) reactive-bonded prepaved high polymer membrane is laid between the initial support and secondary lining as a water-proof layer to prevent the surrounding rock water from seeping into the tunnel.

The tunnel area is located in a karst peak-cluster depression geomorphic region without large topographic fluctuations, surface water, or stable groundwater in the tunnel body or above. The proposed tunnel passes through a steep mountain, and its entrance and exit each are located near the foot of the slope on opposite sides of the mountain. The terrain is relatively low, but there is loose-slope cumulose soil. Open-pit excavation is adopted in the tunnel design. At the entrance to the cavern, pipe shed and small pipe pregrouting has been used to reinforce the fractured rock mass. The development of cracks in the rock surrounding the tunnel body and local corrosion phenomenon may cause water dripping or gushing during the tunnel excavation process. The physical parameters of the proposed tunnel are shown in Table 1.

\section{Geological Hazards and Pretreatment Methods}

3.1. Geological Hazards. The tunnel area is located in a karst peak-cluster depression geomorphic region without large topographic fluctuations, surface water, or stable groundwater in the tunnel body or above. The proposed tunnel passes through a steep mountain, and its entrance and exit each are located near the foot of the slope on opposite sides of the mountain. The terrain is relatively low, but there is loose-slope cumulose soil. Open-pit excavation is adopted in the tunnel design. At the entrance to the cavern, pipe shed and small pipe pregrouting has been used to reinforce the fractured rock mass. The development of cracks in the rock surrounding the tunnel body and local corrosion phenomenon may cause water dripping or gushing during the tunnel excavation process. The physical parameters of the proposed tunnel are shown in Table 1.

The engineering geology of the Hebai Expressway tunnels is complicated, such that it is difficult to ascertain the development, basic form, scale, and distribution of karst and faults. Therefore, many unforeseen geological abnormalities have appeared during construction. Since tunnel excavation began, many hazards have occurred, such as collapse, water and mud inrush, and surface subsidence.

(1) Tunnel Collapse. If there are karst caverns along the tunnel excavation route, the filler in the caverns may flow into the tunnel during excavation, and the tunnel may collapse as a result. Tunnel collapse can lead to further difficulties in tunnel construction, and even to subsequent larger-scale collapse. Figures 2 and 3 show the karst caverns around the tunnel. Most of the caverns are distributed toward the top of tunnel, while others appeared at the sides of the arch, and a few at the bottom.

(2) Water and Mud Inrush. Karst caverns have various internal fillers-particularly water and slurry. Because of being disturbed by tunnel construction, water and slurry may flow into the tunnel through cracks between the tunnel wall and karst cavern. If an effective treatment is not applied to prevent water and slurry from flowing into the tunnel, these cracks may develop into a large hole in the cavern and lead to water and mud inrush.

(3) Surface Subsidence. Surface subsidence is a geological hazard that occurs during tunnel excavation around karst caverns. The construction can cause large disturbances, which may cause the soil above to collapse into the karst caverns [22]. This collapse can also induce large settlement and thereby cause surface subsidence. During Hebai tunnel construction, surface subsidence was seen around the tunnel area. As shown in Figure 4, a large pit approximately 


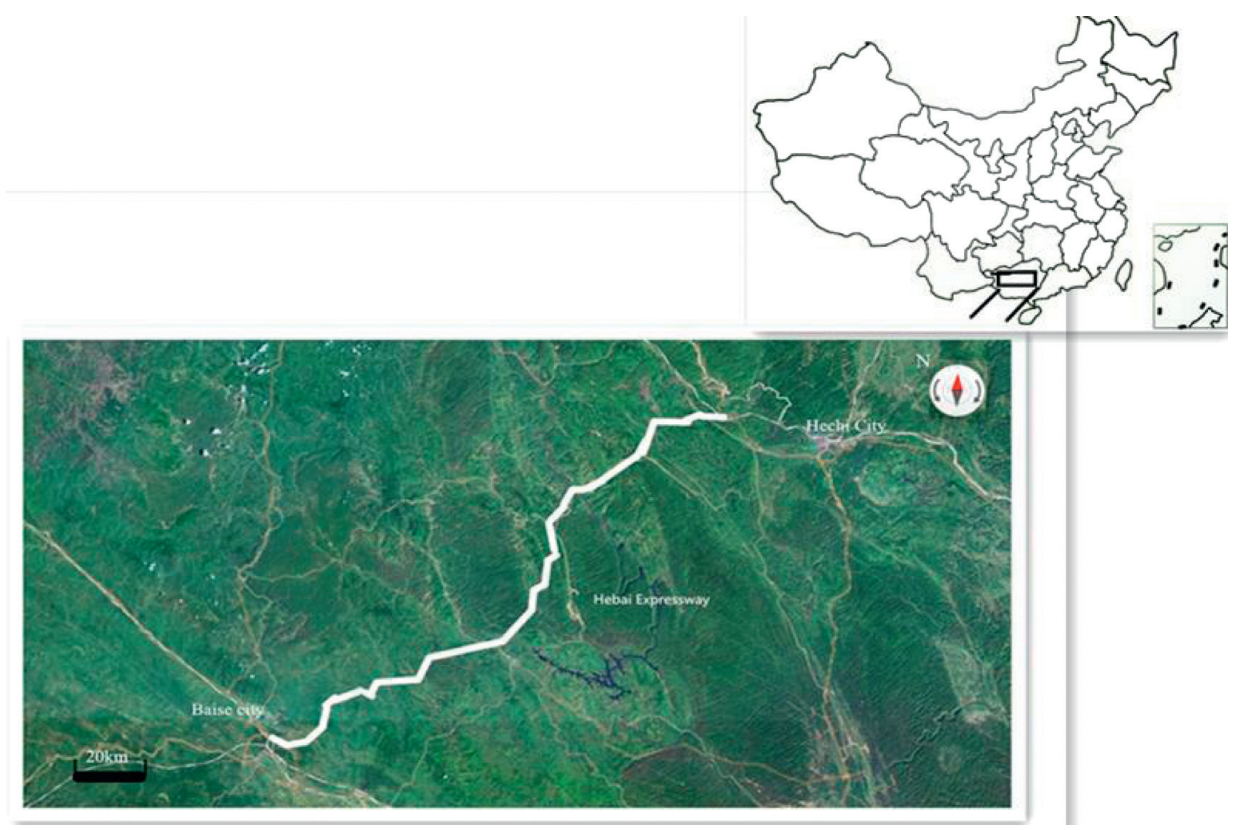

Figure 1: The location of the Hebai tunnel.

TABLE 1: Physical and mechanical parameters.

\begin{tabular}{lccccc}
\hline Material & $\begin{array}{c}\gamma \\
\left(\mathrm{kN} \cdot \mathrm{m}^{3}\right)\end{array}$ & $E(\mathrm{GPa})$ & $\mu$ & $\begin{array}{c}f_{t} \\
(\mathrm{MPa})\end{array}$ & $\begin{array}{c}f_{c} \\
(\mathrm{MPa})\end{array}$ \\
\hline Surround rock grade IV & 22.0 & 2.4 & 0.33 & 85.00 & 28.00 \\
Second lining (C40) & 26 & 31.5 & 0.2 & 2.20 & 23.40 \\
Initial support (C25) & 25 & 28.5 & 0.2 & 1.78 & 16.70 \\
Fill (C15) & 23 & 22.0 & 0.16 & 1.27 & 10.00 \\
\hline
\end{tabular}

$\gamma$ : surrounding rock bulk density; $E$ : elastic modulus; $\mu$ : Poisson's ratio of rock; $f_{t}$ : tensile strength; $f_{\mathrm{c}}$ : compressive strength.

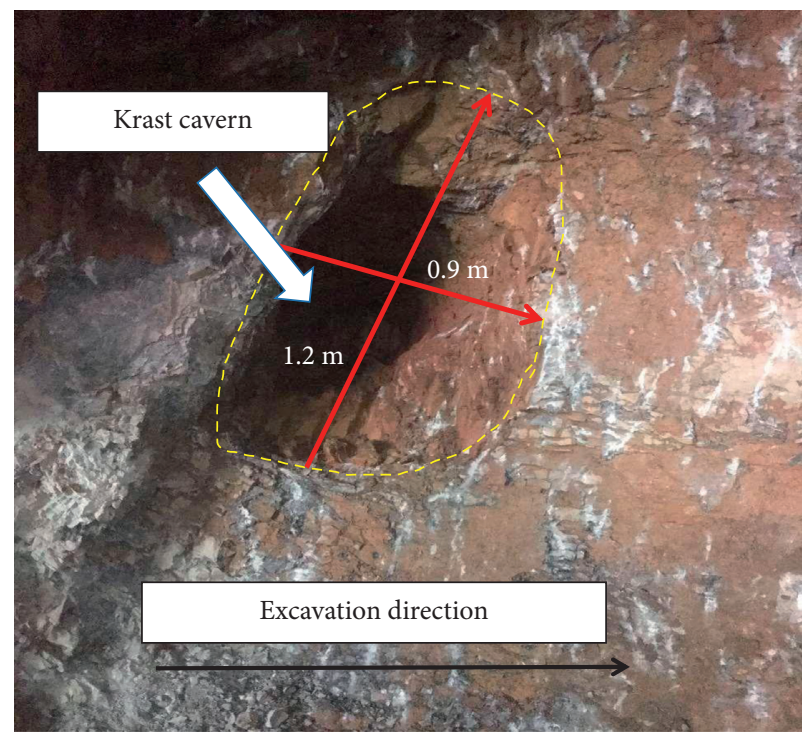

Figure 2: Karst caverns at the top of the right lane cave of the Hebai tunnel.
$2.4 \mathrm{~m}$ long and $1.1 \mathrm{~m}$ wide was observed that could lead to serious casualties and even threaten the safety of surrounding buildings. Therefore, it is necessary to take action to prevent surface subsidence.

3.1.1. Construction Emergency Plan. These hazards-collapse, mud and water inrush, and surface subsidence-often occur unexpectedly during tunnel construction and have a great impact on construction safety. The new Austrian tunneling method is applied to tunnel excavation. The new Austrian tunneling method must implement a policy of "safety first, prevention first" and formulate corresponding emergency plans.

3.1.2. Construction Scheme under Special Geological Conditions. Concrete, masonry, or dry masonry is generally used as backfill when a tunnel passes through a waterless karst cavern with a small span and no development. It is unnecessary to set up special drainage measures when a tunnel passes through a karst cavern with low water content. According to the difference of intersection position between karst cavern and tunnel, concrete is used to fill the cavern and protect the steel arch centering. Various measures, such as sandblasting and grouting with reserved grouting holes, can also be used to fill the cavern. The scale of a karst caves is typically large, and there are a large number of unstable fillings. As such, the support of a large pipe shed or pile foundation towing beam is often used to span the cave. Because the proposed tunnel section is located in the karst development area, there is karst cavern growth in the tunnel. 

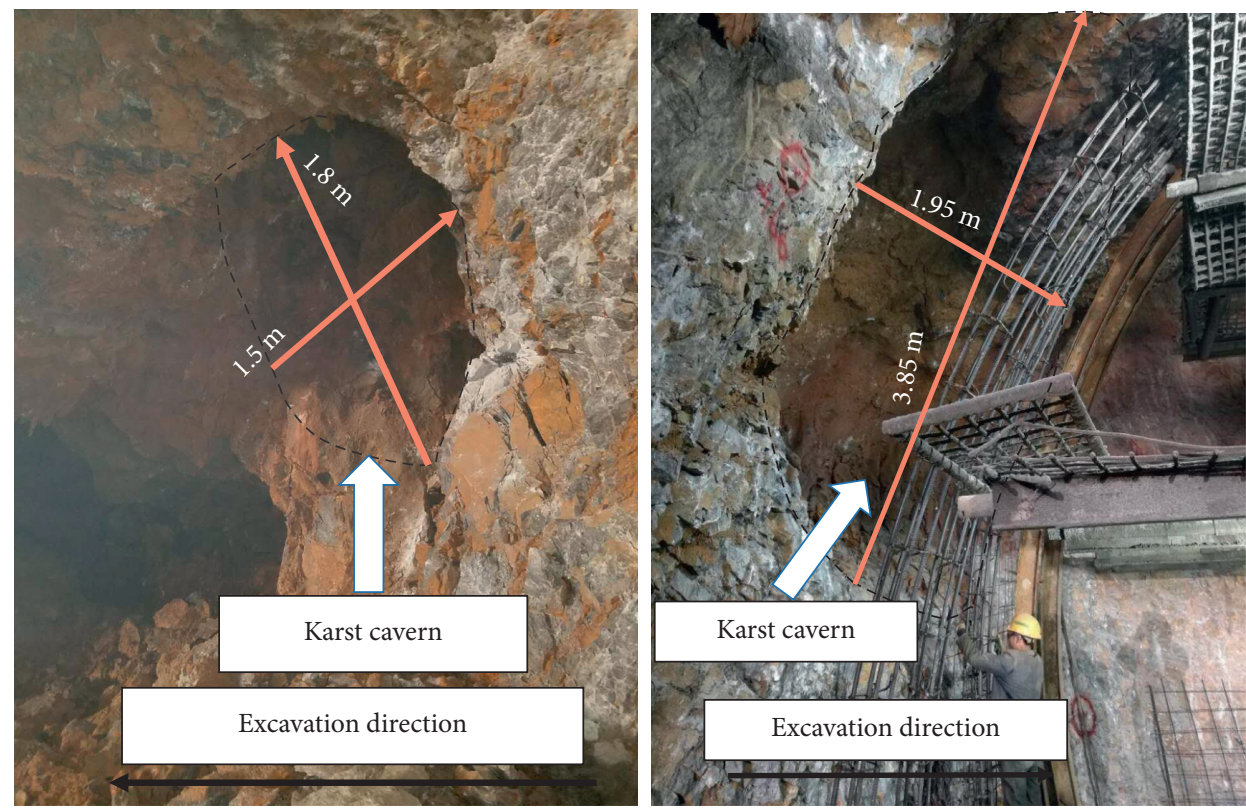

Figure 3: Cave at arch waist of the Hebai tunnel.

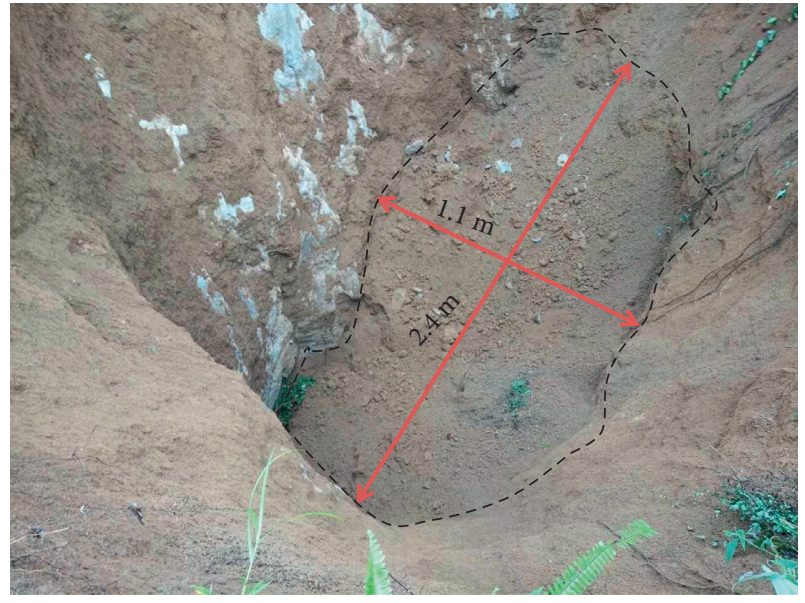

FIGURE 4: Surface subsidence around the Hebai tunnel.

In the construction process, Tunnel Seismic Prediction (TSP) [23-25] should be strengthened within $15-30 \mathrm{~m}$ in front of the tunnel face such as palm face advance drilling and geological radar. Monitoring and measurement procedures for surrounding rock must be strictly implemented, and the construction waste must be removed in time. Construction should be guided by the monitoring and measuring of the surrounding rock, and the design should be revised promptly when necessary.

\subsection{Pretreatment Method}

3.2.1. Treatment of Small Karst Caverns. The proposed treatment scheme primarily aims at karst caverns outside the tunnel excavation surface-above the arch, and under the foundation and pavement-at a depth of less than $2.0 \mathrm{~m}$, and those developed at the tunnel sidewalls. In principle, the backfilling method is used to fill the karst caverns.
(1) Cavern Development above the Arch Waist. In this scenario, as shown in Figure 5, C15 concrete is pumped to backfill the karst cavern to avoid excessive local pressure on the composite lining caused by backfilling with concrete. According to the size of the cavern, the bolt spacing was approximately every $1.2 \mathrm{~m}$ around the cavern, and each bolt was at least $1.0 \mathrm{~m}$ deep into the surrounding rock. After backfilling, shotcrete and steel mesh initial supports are applied.

(2) Cavern Developed at the Tunnel Sidewall. In this scenario, as shown in Figure 6, C15 concrete backfill is used at a thickness of at least $1.5 \mathrm{~m}$. A $\Phi 100$ highdensity polyethylene (HDPE) double-wall perforated bellow is also set up to connect with the side ditch every $2.0 \mathrm{~m}$. On this basis, the shotcrete and steel mesh initial support can be omitted.

(3) Cavern Developed under the Foundation and Pavement. In this scenario, as shown in Figure 7, C15 concrete is used to backfill. If there is filling material, it must first be excavated. A double-wall perforated bellow of $\Phi 100 \mathrm{HDPE}$ is arranged every $2.0 \mathrm{~m}$ and interconnected.

3.2.2. Large Karst Cavern above Arch Waist. This treatment scheme is mainly aimed at karst caverns located above the arch waist or outside the tunnel excavation surface that have a development depth of greater than $2.0 \mathrm{~m}$, and width less than that of the excavation face of the tunnel.

(1) Large Water-Filled Karst Cavern. In this scenario, as shown in Figure 8, C25 concrete is pumped to a minimum thickness of $200 \mathrm{~cm}$. The concrete on both sides of the cavern must be embedded at least $50 \mathrm{~cm}$ into the rock, at a bolt spacing of approximately 


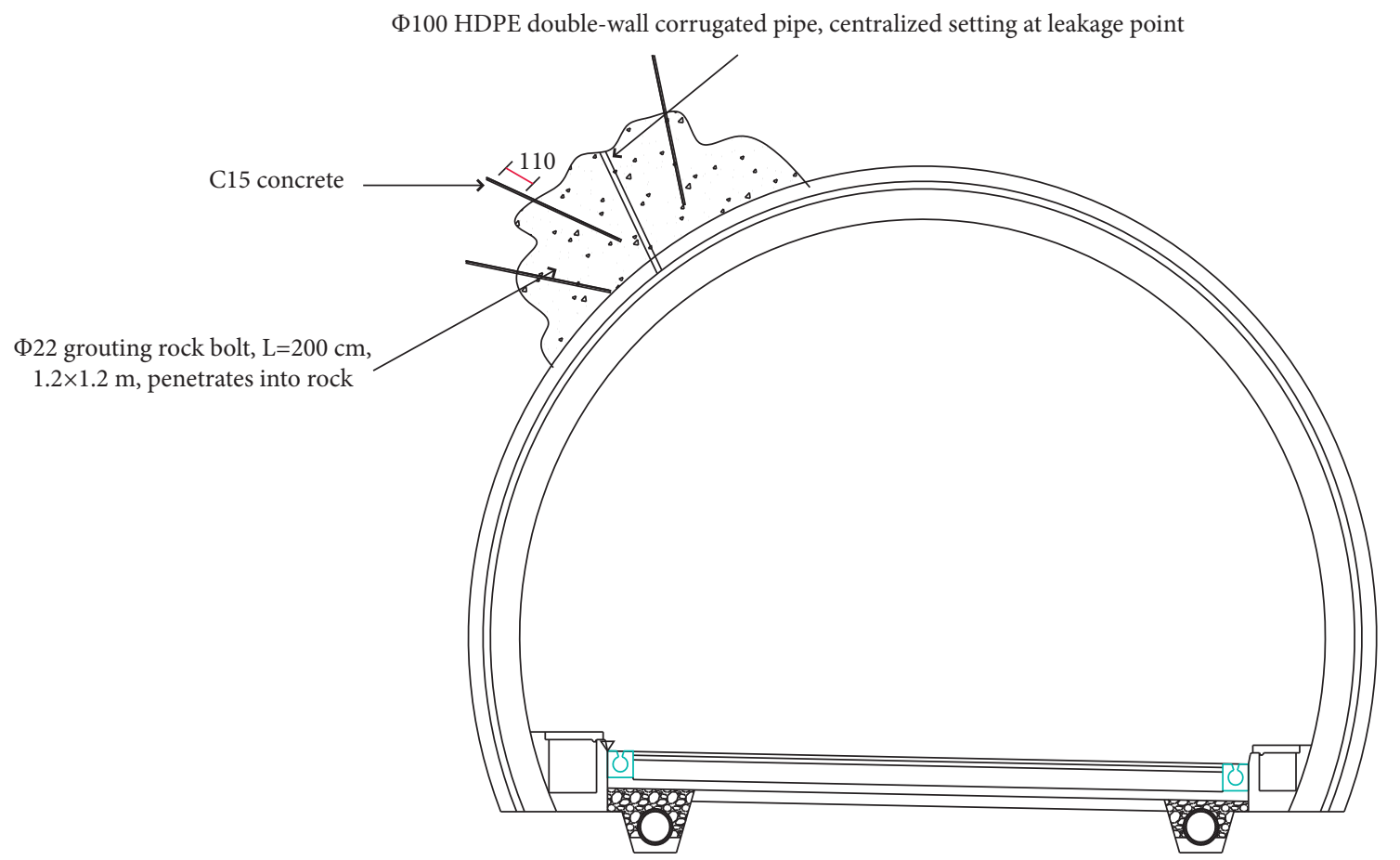

FIGURE 5: Small karst cavern above the arch waist.

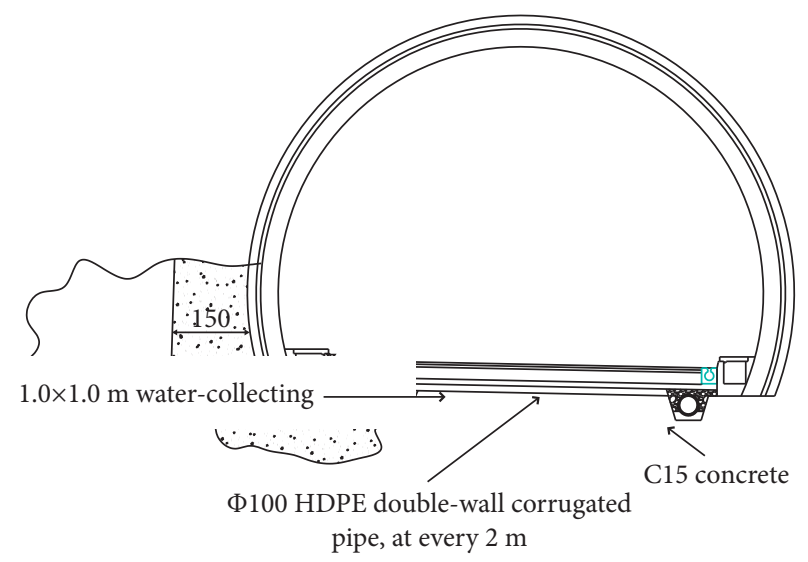

FIGURE 6: Small karst cavern at the sidewall.

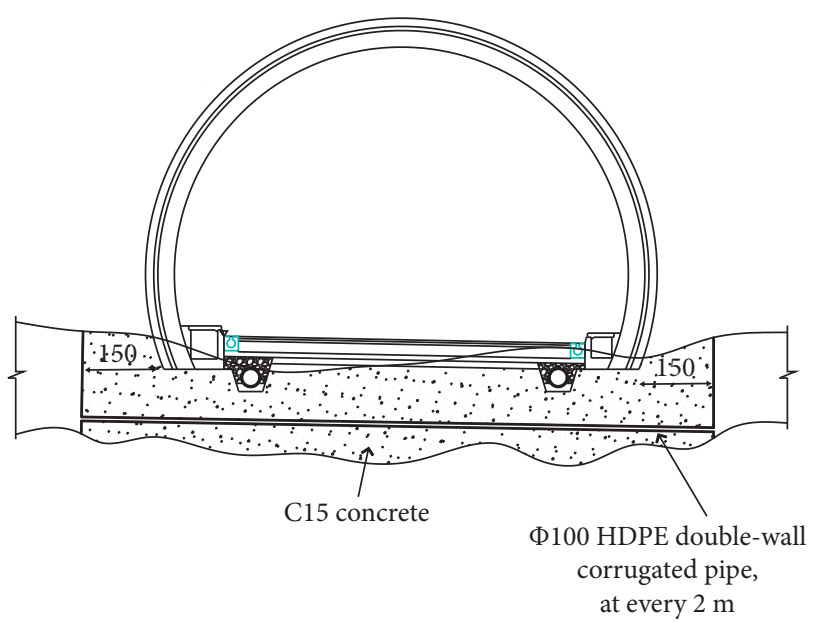

FIGURE 7: Small karst cavern at base.
$1.2 \mathrm{~m}$. The embedded depth of each bolt should be at least $1.5 \mathrm{~m}$. Subsequently, the initial support-such as concrete and steel mesh-will be settled onto the original structure. Expansion of this tunnel section has karst cavern, and $\Phi 800$ steel pipe is preburied at the bottom of the tunnel to connect the original karst cavern waterway.

(2) Empty Karst Cavern above Arch Waist. In this scenario, as shown in Figure 9, C25 concrete is pumped to a minimum thickness of $80 \mathrm{~cm}$. The concrete on both sides of the cavern must be embedded at least $50 \mathrm{~cm}$ into the rock at a bolt spacing of approximately $1.2 \mathrm{~m}$. The depth of each bolt should be at least $1.5 \mathrm{~m}$. Subsequently, the initial support-such as concrete and steel mesh-will be settled onto the original structure. A double-wall perforated bellow of $\Phi 100 \mathrm{HDPE}$ is embedded in advance.

3.2.3. Large Karst Caverns above Arch Waist and below Base. This treatment scheme is primarily aimed at karst caverns located above the arch waist and below the base of the tunnel. The former have features such as a development depth of more than $2.0 \mathrm{~m}$ and width less than that of the tunnel excavation surface, while the latter have a development depth of more than $5.0 \mathrm{~m}$ and width less than that of the tunnel excavation surface.

(1) Karst Cavern under the Tunnel Base. In this scenario, as shown in Figure 10, such a cavern can be passed over by setting up a reinforced concrete slab bridge. To ensure stable contact between the bridge slab ends and foundation, the bearing capacity of the base must exceed $1200 \mathrm{kPa}$. 


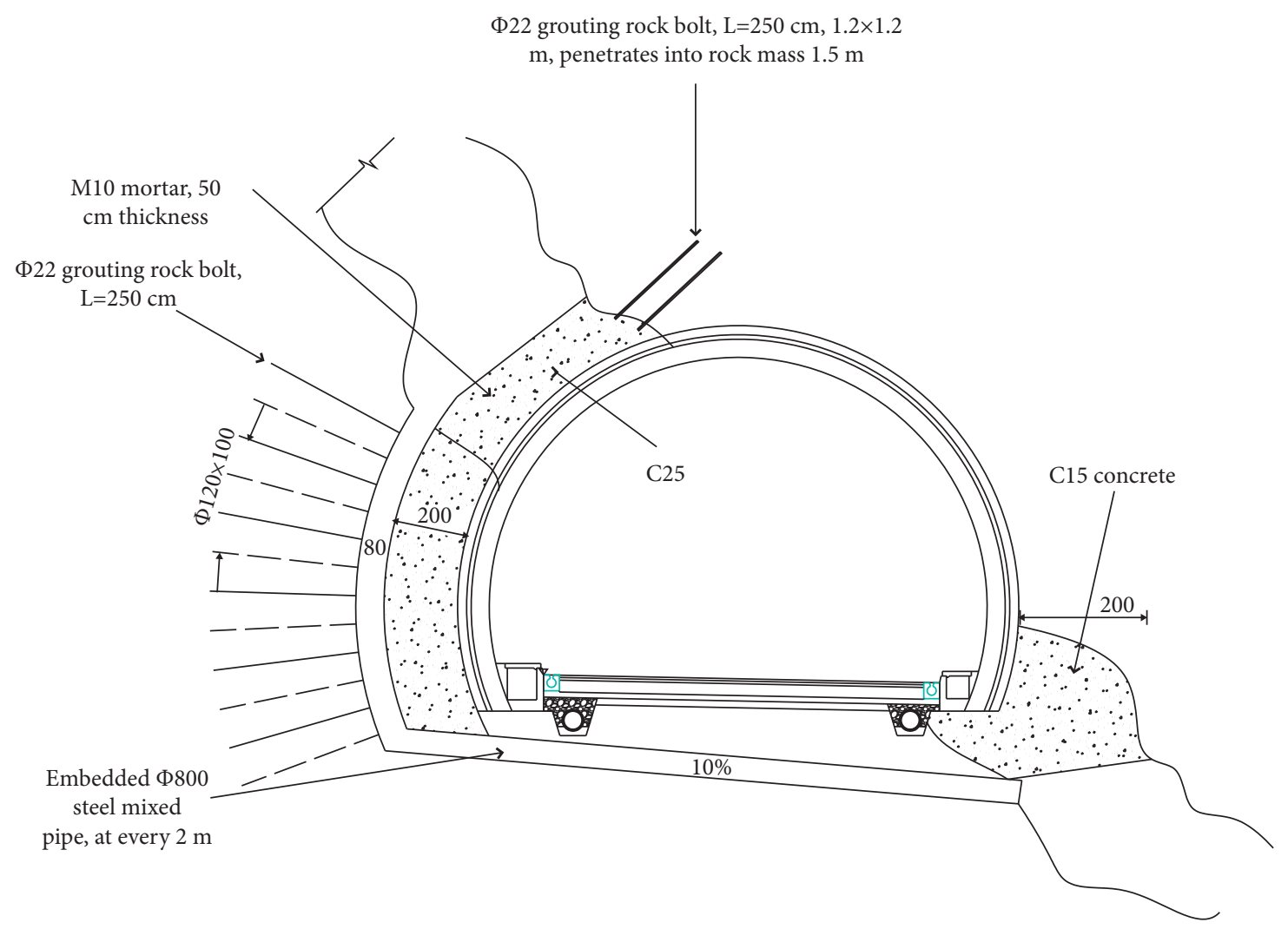

FIgURE 8: Large water-filled karst cavern above arch waist.

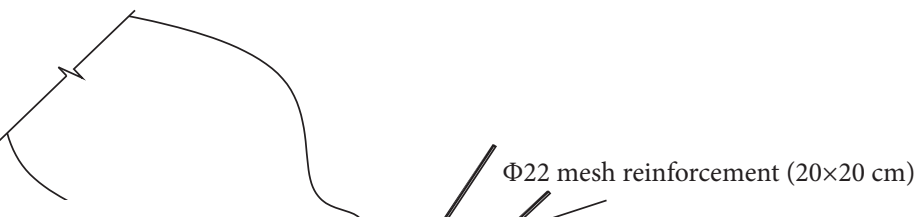

Ф100 HDPE double-wall corrugated pipe, at every

$2 \mathrm{~m}$

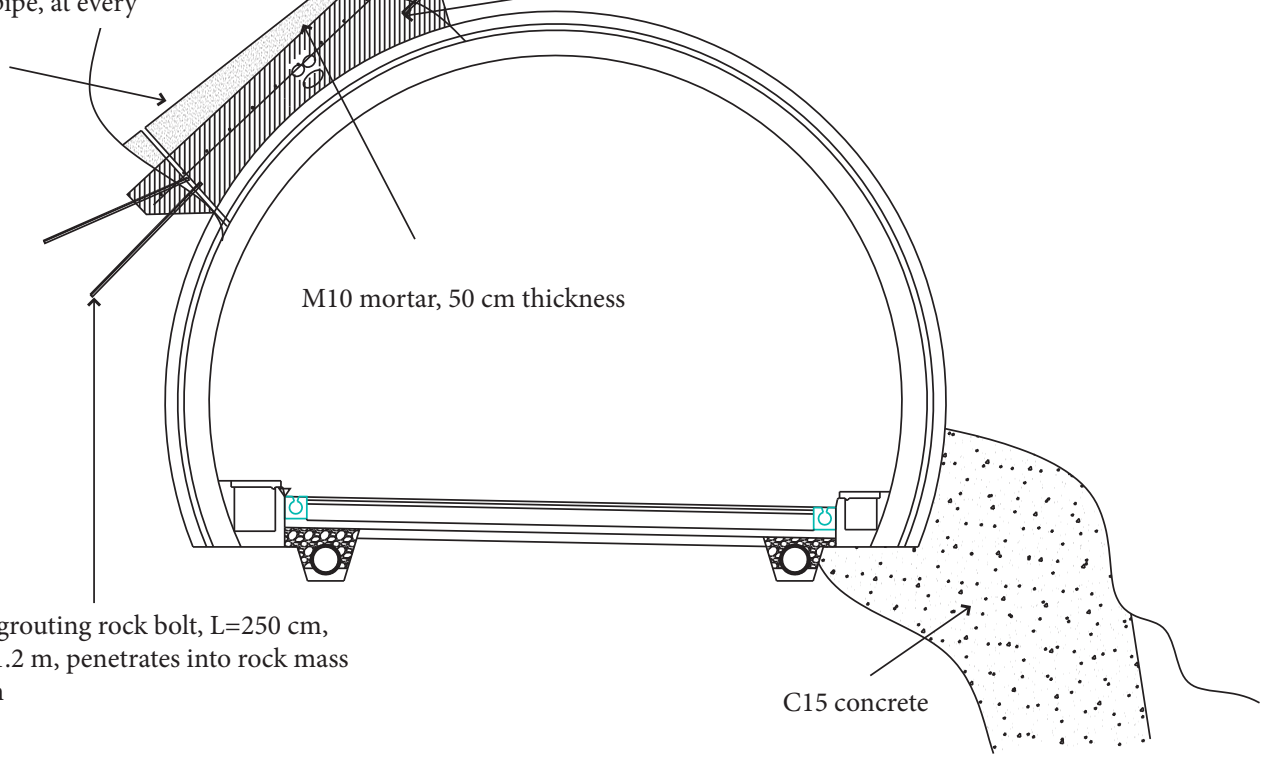

FIGURE 9: Large, empty karst cavern above arch waist. 


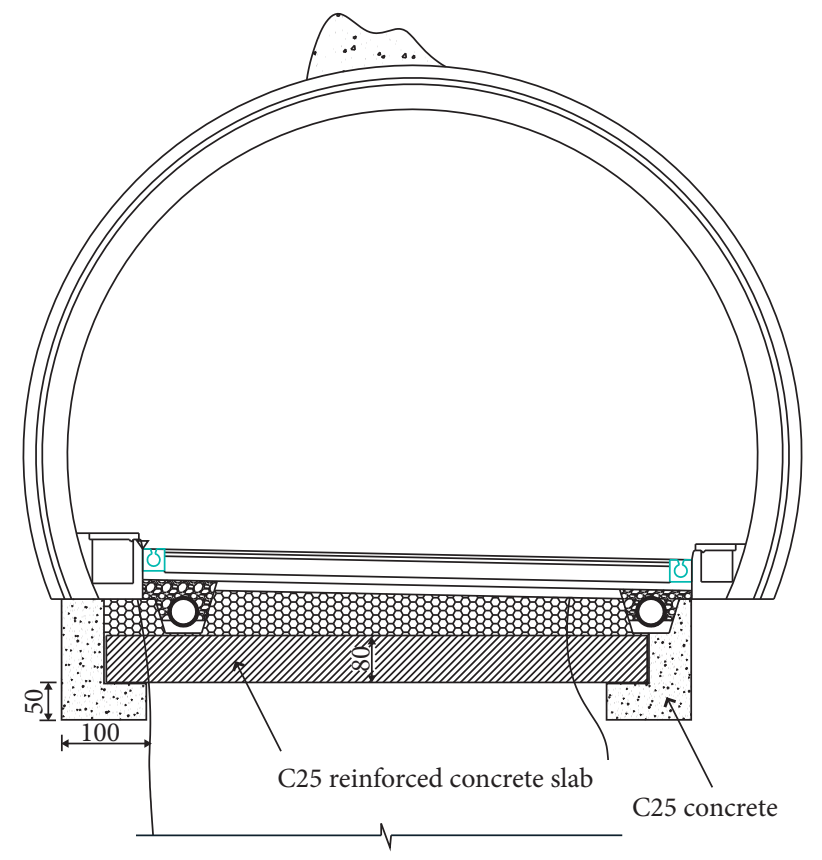

FIgURE 10: Large karst cavern below the tunnel base.

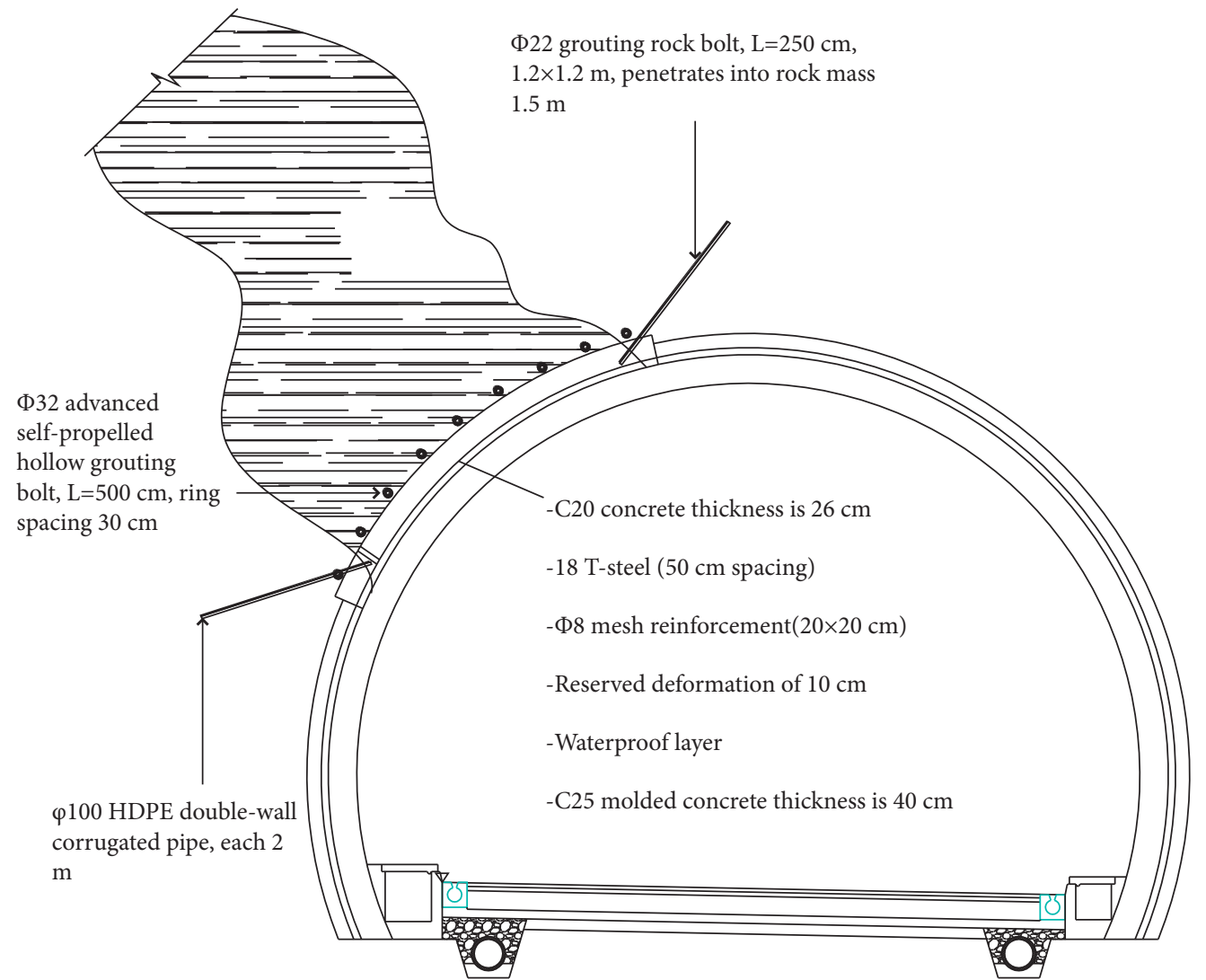

FIGURE 11: Large karst cavern above arch waist (with filler).

(2) Filled Karst Cavern above the Arch Waist. In this scenario, as shown in Figure 11, $\Phi 42 \times 4 \mathrm{~mm}$ advanced small pipes are applied horizontally in advance at a spacing of $30 \mathrm{~cm}$. Presplitting blasting is used for excavation, and I18 steel is applied at a distance of $50 \mathrm{~cm}$. Attention should be given to the proper 
expansion of the foot of the steel frame to ensure a solid foundation. A reinforced concrete structure can be considered for a secondary lining with bolts and steel mesh according to the development of the karst caverns. During construction, attention should be given to embedding double-wall perforated bellows of $\Phi 100$ HDPE. Additionally, circular drainage pipes in this area should be increased.

\section{Optimized Treatment for Karst Caverns in Tunnel}

After an on-site investigation and discussion on the location and development of karst caverns, the following opinions have been proposed for the optimized treatment of karst caverns.

4.1. General Principle. The excavation method must be changed to a "three-bench tunneling and reserved core soil method." Such method is necessary to strengthen the supports and form a closed ring as quickly as possible. The length of the upper, middle, and lower steps should be controlled within $3 \mathrm{~m}$, and secondary linings should be installed simultaneously.

\subsection{Optimized Measure}

(1) Change the Thickness of the Initial Support and Secondary Lining and Increase the Reserved Deformation. Because the karst cavern starts at the left sidewall, considering the safety of the construction process and minimization of the disturbance to the initial support and surrounding rock, the supporting methods are as follows.

The left side adopts a $\Phi 108$ large pipe shed lock foot and grouting plug. The length of the pipe shed is determined according to the actual situation on site. However, it is necessary to ensure that the depth of embedded bedrock is at least $2 \mathrm{~m}$. The right arch foot is sealed with a $\Phi 42$ grouting catheter lock foot, and the nozzle is sealed after grouting. By this, the reserved deformation is increased to $20 \mathrm{~cm}$, and the thickness of the second lining is increased to $60 \mathrm{~cm}$ (see Figure 12).

(2) Vault Grouting. Three layers of $\Phi 42$ advanced small pipe are used to consolidate the top and front surface soil of the solution cavity at the left side (the arc length of the solution cavity section is approximately $7 \mathrm{~m}$ ). The lengths and elevation angles of the three small catheter layers are $4 \mathrm{~m}$ at $0^{\circ}, 5 \mathrm{~m}$ at $15^{\circ}$, and $6 \mathrm{~m}$ at $45^{\circ}$ (see Figure 13). Any construction technology—such as steel reinforcement mesh, steel arch support, shotcrete, and reserve pump piping-is applied in advance until the initial concrete strength meets the requirements, followed by sand blowing backfill.

(3) Treatment of Cavern-In Landslides. To ensure that no secondary collapse or mud burst occurs during excavation of the collapsed body, C25 shotcrete is used at a thickness of $20 \mathrm{~cm}$ to seal its surface.

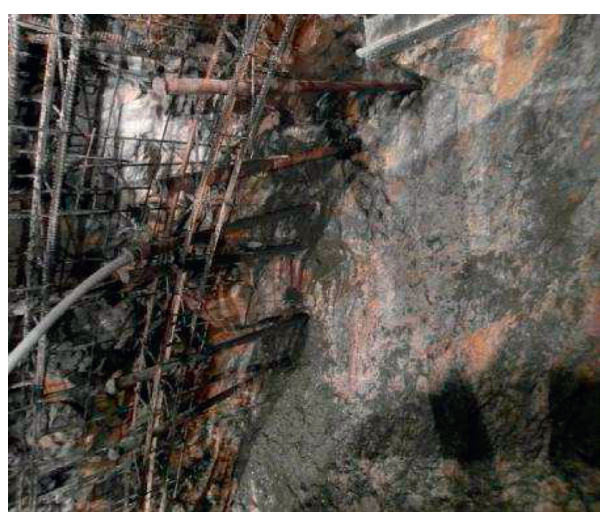

Figure 12: Treatment of karst cavern in the Hebai tunnel.

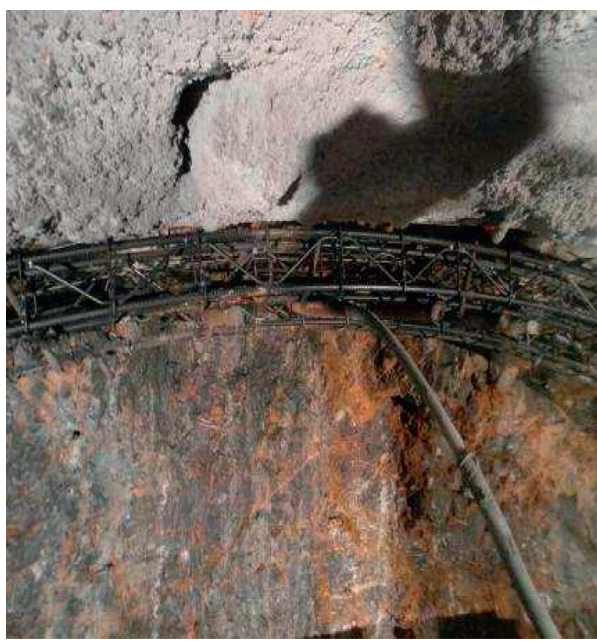

FIGURE 13: Shotcreting on the vault of tunnel face with $\Phi 42$ advanced small pipe.

Subsequently, pregrouting consolidation is performed for the karst cavern and the surrounding rock in front of the tunnel face. The grouting pipe is arranged in a plum-blossom pattern and connected to a $6 \mathrm{~m} \Phi 42$ grouting catheter with an overlap of $2.0 \mathrm{~m}$, and the grouting pipe is arranged in plumblossom pattern. The number of grouting pipes should be increased with a spacing of $0.75 \mathrm{~m}$ appropriately in the position of the left side of dissolution chamber and with a spacing of $1.0 \mathrm{~m}$ in the position of the right side. After ensuring the stability of the collapsed body by grouting, it can be excavated separately.

(4) Measuring and Monitoring in Cavern. During the construction of this section, any changes in the surrounding rock and supports in the tunnel are closely observed. A third-party monitoring and measuring unit should ensure an observation frequency of twice per day. If abnormal conditions are found (such as continuous slagging of the vault, cracking and subsidence of the initial support, and large convergence value), the construction team should be instructed to stop, and the workers and equipment in the tunnel should be withdrawn immediately. 
(5) Surface Collapse Treatment. After the karst section is passed smoothly, and the strength of the second lining reaches $100 \%$, the surface subsidence pit is backfilled with clay to the original ground elevation, and a permanent water interception ditch is set around the original collapsed pit to prevent surface water from infiltrating the tunnel through the pit fissures. After backfilling, vegetation restoration on the surface of the original collapse pit can be performed. For this, Wei et al. [26] suggest that spray-on grass planting be used, and surface subsidence pit is backfilled with clay as shown in Figure 14.

(6) Others. Drainage pipes are buried in the collapsed cavity on the outer side of the initial support. These pipes travel downward along the tunnel wall and connect with the longitudinal drainage pipes. Settlement joints are added in the sudden change section of the surrounding rock. Meanwhile, other settlement joints are added during the construction of the second lining for the section.

4.3. Bolt Calculation of Treating Karst Cave. For the bolt mentioned in this paper, the spacing and embedment depth need to be calculated. The empirical formula used in this project is as follows:

(1) Calculation of Bolt Spacing

$$
N=\frac{(F * P)}{\left(P_{u}\right)},
$$

where $N$ is the spacing of each bolt; $F$ is the safety factor of the project, which is determined according to the engineering specifications; $P$ is the thrust $(\mathrm{kN})$ bearing filler; $P_{u}$ is the ultimate tension load of the bolt, which is determined by experiment.

(2) Calculation of Bolt Length. Calculating anchorage length $L_{1}$ of anchor cable according to bond strength between anchor rod and cement mortar

$$
L_{1}=\frac{\left(F_{1} * P\right)}{\left(\pi d_{s} \tau_{u}\right)},
$$

where $L_{1}$ is the anchorage length $(\mathrm{m}), F_{1}$ is the safety factor of ultimate resistance capacity, and $d_{S}$ is the external diameter of bolt; $\tau_{u}$ is the bond strength between bolt and cement mortar

$$
L=L_{1}+L_{2}
$$

where $L$ is the length (m) of the bolt and $L_{2}$ is the length $(\mathrm{m})$ of the exposed length of the anchor cable.

\section{Optimized Treatment for Karst Caverns in Tunnel}

The tunnel is built in the karst area and will encounter disaster accident of mud bursting and water bursting in front of the tunnel face (Figure 15). In this section, when there is a

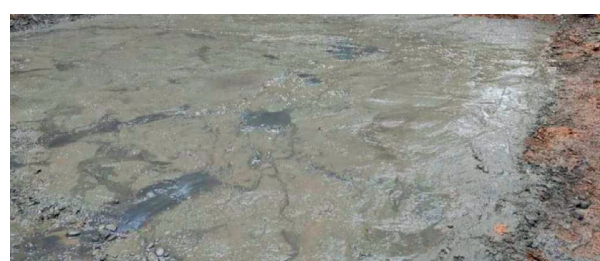

Figure 14: Surface subsidence pit after surface collapse treatment with clay.

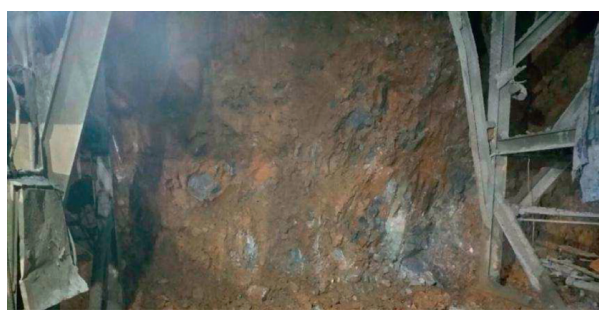

FIGURE 15: Disaster accident of mud bursting and water bursting during tunnel excavation.

pressure karst cavern in front of the tunnel face, based on the stress characteristics of the square rock wall in front of the tunnel face, the calculation formula of the safe thickness of the square rock wall in front of the tunnel face is proposed.

5.1. Computational Model. When the square rock wall in front of the tunnel face is damaged by mud inrush and water inrush, the square rock mass in front of the tunnel face will be damaged by punching, and the failure structure is in the shape of cone platform, as shown in Figure 16. In this section, based on the principle of limit equilibrium, according to the failure shape of rock wall under the condition of water inrush and mud inrush, the calculation formula of safety thickness of square rock wall in front of tunnel face is derived $[27,28]$.

As shown in Figure 16, $h$ is the thickness of the square rock wall in front of the tunnel face, $D$ is the diameter of the tunnel face, $q$ is the cavity pressure, and $\theta$ is the pressure diffusion angle of the punching body, where $\theta=45^{\circ}-\varphi / 2$.

\subsection{Entirety Punching Tensile Failure Model Calculation.} When the rock wall on the tunnel face reaches the limit equilibrium, only the tensile action on the failure surface of the rock wall cutting body is considered. By establishing the limit equilibrium equation on the failure surface (without considering the gravity action of the rock wall), the safe thickness of the rock wall can be obtained.

The side area of the rock wall cutting body is

$$
s=\frac{\pi h}{\cos \theta}(d+h \tan \theta),
$$

where $d$ is the compression diameter.

According to geometric conditions,

$$
D=d+2 h \tan \theta .
$$




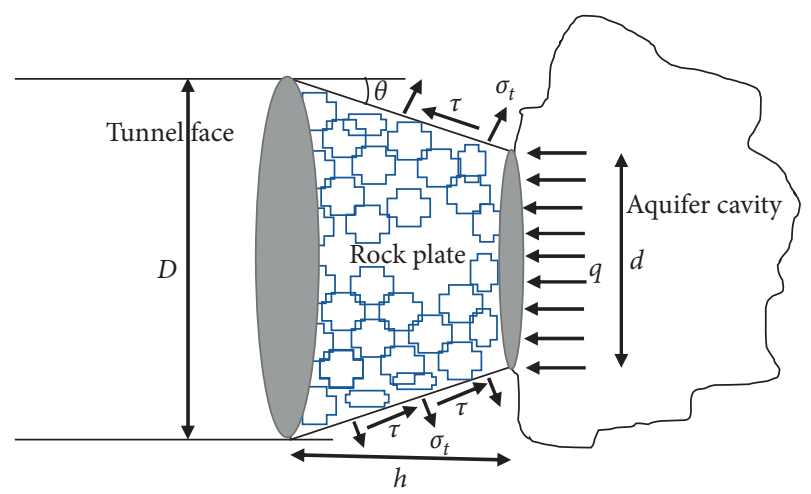

FIgURE 16: Three-dimensional damage model for the slippage of the antiburst wall.

According to the principle of limit equilibrium, there are

$$
q\left(\frac{d}{2}\right)^{2} \pi-P_{t}=\sigma_{t} S \sin \theta
$$

where $\sigma_{t}$ is the tensile strength, $\mathrm{MPa}$, and $P_{t}$ is the support pressure of the face, under the principle of NATM $(0 \mathrm{kN})$.

By substituting formulas (4) and (5) into (6), the minimum outburst prevention thickness of rock wall can be obtained.

5.3. Entirety Punching Shear Failure Model Calculation. When the rock wall on the tunnel face reaches the limit equilibrium, only the shear resistance on the failure surface of the rock wall cutting body is considered. By establishing the limit equilibrium equation on the failure surface (without considering the gravity effect of the rock wall), the safe thickness of the rock wall can be obtained.

According to the principle of limit equilibrium, there are

$$
q\left(\frac{d}{2}\right)^{2} \pi-P_{t}=\tau S \cos \theta .
$$

According to formulas (1) (2), the outburst prevention thickness of the square rock wall in front of the tunnel can be obtained under the shear failure mode.

\subsection{Entirety Punching Shear Failure Model and Tensile Failure} Model Calculation. When the rock wall on the tunnel face reaches the limit equilibrium, considering the joint action of tension and shear on the failure surface of the rock wall cutting body, the safe thickness of the rock wall can be obtained by establishing the limit equilibrium equation on the failure surface (without considering the gravity effect of the rock wall).

According to the principle of limit equilibrium, there are

$$
q\left(\frac{d}{2}\right)^{2} \pi-P_{t}=S\left(\tau \cos \theta+\sigma_{t} \sin \theta\right) .
$$

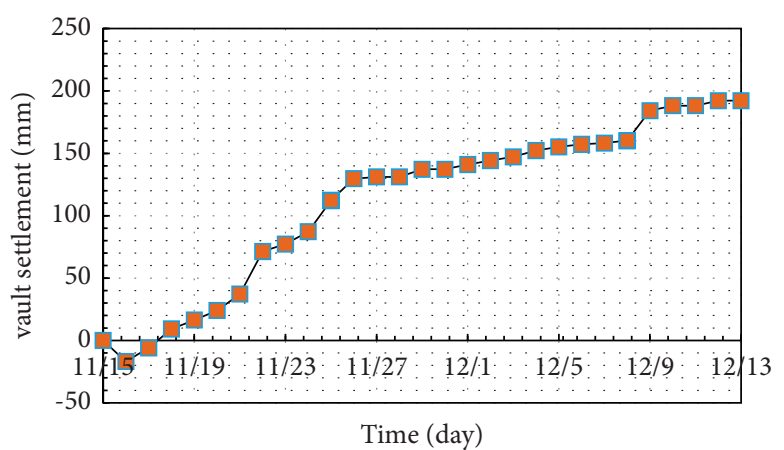

FIGURE 17: Vault settlement variation of Karst cave area with being treated.

According to formulas (4) (5), the outburst prevention thickness of the square rock wall in front of the tunnel can be obtained under the shear failure mode.

The safety thickness of rock wall is affected by the diameter of tunnel, pressure of solution cavity, tensile strength, internal friction angle, and shear strength. The safety thickness of rock wall is linearly related to the tunnel diameter; the safety thickness of rock wall decreases with the increase of tensile strength, shear strength, and internal friction angle; the safety thickness of rock wall increases with the increase of cavity pressure and tunnel diameter, and the safety thickness of rock wall is relatively affected by shear strength. After calculating the safe thickness of the tunnel face, the support parameters for the surrounding rock of the tunnel face can be carried out.

\section{Effect of Optimized Treatment Applied for Karst Caverns}

There was a high-liquid-limit clay-filling karst cavern at the tunnel sidewall at sections $\mathrm{K} 103+133 \sim \mathrm{K} 103+137$, and its direction was from left to right. Figure 17 shows the vault settlement at section $\mathrm{K} 103+130$, which was set up on November 15, 2018. The settlement progressed rapidly over 10 days and exceeded the tolerance value that was set by the local government. The settlement progressed rapidly with a daily variation of less than $5 \mathrm{~cm}$ and exceeded the $80 \mathrm{~cm}$ tolerance value set by the local government.

The proposed optimized measure was applied for this karst cavern. After being treated, the daily variation value normalized, indicating that the settlement variation and risk of excavation had decreased.

Monitoring and measuring continued until the second lining was done. After 11 days, the vault settlement variation results indicated that the settlement had stabilized, and the optimized measure had produced a favorable result for the karst cavern at sections $\mathrm{K} 103+133 \sim \mathrm{K} 103+137$.

\section{Conclusions}

(1) Tunnel construction in karst regions may result in serious geohazards. Tunnel construction in cavernous karst covered by sandy soil has induced such geohazards in Guangxi Province, including tunnel 
collapse, water or mud inrush, ground collapse, and long-term instability.

(2) In the present study, karst caverns in the Hebai tunnels were succinctly analyzed and investigated on the basis of size, shape, lithology, and internal filler.

(3) According to the location, size, and internal filling of a karst cavern, different pretreatment methods were set for different situations. In the construction process, the cavern can be prepared in advance so as not to delay the project.

(4) The calculation model of karst cave in front of tunnel face is established, and it is divided into three cases to deduce, and the safe rock thickness of actual tunnel face is calculated. According to the safe thickness of the tunnel face, some support is carried out for the surrounding rock of the tunnel face.

(5) Through on-site inspection and characterization of karst caverns, specific and appropriate schemes were formulated to fill and reinforce the caverns in a timesensitive manner. The optimized treatment applied on the Hebai tunnel produced a favorable result. Following treatment, the site should be monitored to determine whether the surrounding rock is stable. However, the treatments may be not suitable for karst caves filled with mud or soils.

\section{Data Availability}

The data used to support the findings of this study are available from the corresponding author upon request.

\section{Conflicts of Interest}

The authors declare that they have no conflicts of interest.

\section{Acknowledgments}

This work was supported by the National Natural Science Foundation of China (Nos. 52078211 and 51909087), the Natural Science Foundation of Hunan Province, China (Grant Nos. 2020JJ4021 and 2021JJ40201), Science and Technology Progress and Innovation Project of Transport Department of Hunan Province (202009), Open Fund of National Engineering Laboratory of Highway Maintenance Technology (Changsha University of Science \& Technology, kfj190107), and Scientific Research Projects of Hunan Education Department (18K064).

\section{References}

[1] Y. R. Lu, China Karst, Higher Education Press, Beijing, China, 2010, in Chinese.

[2] P. Milanovic, Geological Engineering in Karst, Zebra Publishing Ltd, New York City, USA, 2000.

[3] J. M. Huang, M. N. Lü, G. Yu, and X. Y. Chen, "Research on the reason for geologic disasterby karst surface collapse at Jinshazhou in Guangzhou," Carsologica Sinica, vol. 32, no. 2, pp. 167-174, 2013.
[4] M. H. Li and J. Y. Du, "Geological issues on environmental engineering of karstdeep foundation pit and its control measures," Guizhou Geol, vol. 21, no. 3, pp. 188-190, 2004, in Chinese.

[5] I. Yilmaz, "GIS based susceptibility mapping of karst depression in gypsum: a case study from Sivas basin (Turkey)," Engineering Geology, vol. 90, no. 1-2, pp. 89-103, 2007.

[6] I. Yilmaz, M. Marschalko, and M. Bednarik, "Gypsum collapse hazards and importance of hazard mapping," Carbonates and Evaporites, vol. 26, no. 2, pp. 193-209, 2011.

[7] R.G. KooshaK, R. Ghasemizadeh, L. Rajic, and A. Alshawabkeh, "Assessment of groundwater quality and remediation in karst aquifers: a review," Groundwater for Sustainable Development, vol. 8, pp. 104-121, 2018.

[8] K. I. Song, G. C. Cho, and S. B. Chang, "Identification, remediation, and analysis of karstsinkholes in the longest railroad tunnel in South Korea," Engineering Geology, vol. 135-136, pp. 92-95, 2012.

[9] Q. Wu, Y. Z. Liu, D. H.. Liu, and W. Zhou, "Prediction of floor water inrush: the application of GIS-based AHP vulnerable index method to Donghuantuo CoalMine, China," Rock Mechanics and Rock Engineering, vol. 44, no. 5, pp. 591-600, 2011.

[10] J. Zhao, Q. M. Gong, and Z. Eisensten, “Tunnelling through a frequently changing and mixed ground: a case history in Singapore," Tunnelling and Underground Space Technology, vol. 22, no. 4, pp. 388-400, 2007.

[11] J. Ma, J. Guan, J. Duan, L. Huang, and Y. Liang, "Stability analysis on tunnels with karst caves using the distinct lattice spring model Stability analysis on tunnels with karst caves using the distinct lattice spring model," Underground Space, vol. 6, no. 11, pp. 1-26, 2020.

[12] J. Y. Li, T. Y. Li, C. C. Shen et al., "Variations and significance of $\mathrm{Mg} / \mathrm{Sr}$ and $87 \mathrm{Sr} / 86 \mathrm{Sr}$ in a karst cave system in southwestern China," Journal of Hydrology, vol. 2021, Article ID 126140, 2021.

[13] Y. Zheng and S. He, "Characteristics, challenges and countermeasures of giant karst cave: a case study of Yujingshan tunnel in high-speed railway," Tunnelling and Underground Space Technology, vol. 2021, Article ID 103988, 114 pages, 2021.

[14] Q. L. Cui, S.-L. Shen, Y. Xu, H.-N. Wu, and Z.-Y. Yin, "Mitigation of geohazards during deep excavations in karst regions with caverns: a case study," Engineering Geology, vol. 195, pp. 16-27, 2015.

[15] Á Tóth, Q. Gong, and J. Zhao, "Case studies of TBM tunneling performance in rock-soil interface mixed ground," Tunnelling and Underground Space Technology, vol. 38, pp. 140-150, 2013.

[16] B. Miguel, S. Carlos, B. Gerardo et al., "Effects of glaciation on karst hydrology and sedimentology during the last glacial cycle: the case of granito cave, central pyrenees (Spain)," Catena, vol. 206, 2021.

[17] M. D. Bolton, S. Y. Lam, P. J. Vardanega, C. W. W. Ng, and $\mathrm{X}$. Ma, "Ground movementsdue to deep excavations in Shanghai: design charts," Frontiers of Structural and Civil Engineering, vol. 8, no. 3, pp. 201-236, 2014.

[18] S. L. Shen, H. N. Wu, Y. J. Cui, and Z. Yin, "Long-term settlement behavior of the metrotunnel in Shanghai," Tunnelling and Underground Space Technology, vol. 40, pp. 309323, 2014

[19] I. Yilmaz and M. Marschalko, “A leaning historical monument formed by undergroundmining effect: an example from 
Czech Republic," Engineering Geology, vol. 133-134, pp. 43-48, 2012.

[20] L. Y. Wei, L. J. Han, J. L. Ran, S. Yang, and C. Zheng, "Comprehensive geological prediction of filling cavity and treatment of mud inrush for yangling tunnel," Journal of Basic Science and Engineering, vol. 24, no. 6, pp. 1256-1267, 2016, in Chinese.

[21] W. Luo, "Study on treatment measures of karst cave in deep foundation pit," Railway Siyuan Survey and Design Group, vol. 1, pp. 88-91, 2012, in Chinese.

[22] M. Marschalko, I. Yilmaz, M. Bednarik, K. Kubečka, T. Bouchal, and Z. Jaroslav, "Subsidence map of underground mining influence for urban planning: an example fromthe Czech Republic," The Quarterly Journal of Engineering Geology and Hydrogeology, vol. 45, no. 2, pp. 231-241, 2012.

[23] X. P. Zhou, X. C. Huang, P. F. Liu, and T. F. Li, "A probabilistic method to analyze collapse failure of shallow rectangular tunnels," Tunnelling and Underground Space Technology, vol. 82, pp. 9-19, 2018.

[24] X. P. Zhou, X. C. Huang, and J. X. Li, "Reliability assessment of tunnel based on P-wave seismic velocity," International Journal of Geomechanics, vol. 11, Article ID 06018030, 2018.

[25] X. C. Huang, D. Y. Lei, Y. P. Xie, Q. N. Chen, and Y. Cao, "Intelligence early-warning of underground caverns collapse failure considering the variables multicollinearity," Journal of Basic Science and Engineering, vol. 29, no. 5, pp. 1-17, 2021.

[26] Y. Wei, L. F. Yu, J. C. Zhang, Y. Yu, and D. L. Deangelis, "Relationship between vegetation restoration and soil microbial characteristics in degraded karst regions: a case study," Pedosphere, vol. 21, no. 1, pp. 132-138, 2011.

[27] Z. H. Yang, X. L. Yang, J.-S. Xu, Y.-X. Li, and Z. Sun, "Two methods for rock wall thickness calculation in karst tunnels based on upper bound theorem," Rock and Soil Mechanics, vol. 38, no. 3, pp. 801-880, 2017.

[28] Z. J. Wang, J. Y. Gao, P. Zhang, X. Guan, and X. F. Ji, "Stability analysis of tunnel face in high-pressure karst tunnels based on catastrophe theory," Yantu Gongcheng Xuebao/Chinese Journal of Geotechnical Engineering, vol. 41, 2019. 